\title{
EDITORIAL
}

\section{Welcome to Barcelona}

\author{
Josep Martin Comin
}

Published online: 7 August 2009

(C) Springer-Verlag 2009

Welcome to Barcelona. You are lucky; your visit to Barcelona can be an outstanding experience. Catalunya and Barcelona have an old history of combining different things. In Barcelona you will have the opportunity to combine work and pleasure, food and wine, fish and meat, mountain and sea. During this congress you will have the opportunity to enjoy all the treasures of one of the most beautiful cities in the world.

Barcelona was founded more than 2,000 years ago. The first inhabitants, Iberians, were called the "laietanos". The legend says that the name of the city probably came from the Carthaginian general Amilcar Barca. Perhaps it is just a coincidence, but a "barca" in the Catalan language is a boat. This is maybe the reason, since Barcelona has always been (especially so in recent years) open to the sea, to the Mediterranean, as you will find when you visit the conference center.

During these two millennia Barcelona has hosted various cultures-from the "laietanos" to the Romans, Jews, Muslims, Visigoths.... and, of course, the Catalans. Catalunya's limits were fixed in the 12th century. Today, Barcelona is the capital of Catalunya, and is one of the main Mediterranean cities.

During your stay, please visit the "Barrio gotico" (Gothic quarter) and you will understand why Barcelona is proud of its history. From the King's Square to the Sant Felip Neri corner, visiting the Cathedral, and Santa Maria del Mar, you can discover and enjoy Barcelona's past. There are so many beautiful sites that we cannot list all of them. Let me remind

J. Martin Comin $(\square)$

Hospital U. Bellvitge, Nuclear Medicine Department,

Hospitalet de Llobregat,

08907 Barcelona, Spain

e-mail: jmartincomin@bellvitgehospital.cat you that Barcelona is the center of Modernisme, the cultural architectural movement that flourished between 1880 and 1930. The Palau de la Música (Music Palace) from the architect Domènech I Montaner and the spectacular creations of Antoni Gaudí (Casa Milà, Casa Batlló, Parc Guell...) as well as all of the buildings surrounding the city center give Barcelona a part of its unique personality. Today Barcelona shows its new image to the world. Modern building designs give new life to Barcelona. The city sea façade was renovated for the Olympic Games in 1992, and a few years later, the forum area, where the congress takes place, hosted the World Culture Forum, and the city gained another cultural landmark.

On the other hand, Catalunya is the home of the Nova Cuina-some of the most world-famous chefs are from Catalunya. The traditional cuisine where the flavors of country and sea, fish and meat (mar i muntanya) were mixed has allowed the genial creations of the new cuisine where many flavors may be constructed and deconstructed to give life to a new spectacular dish. Please take the time to enjoy the traditional as well as the new Catalonian cuisine, which is famous all over the world.

Sports are also important for the Catalan people. Barcelona's sports club, Barça, is known all over the world, especially in football, but also in basketball, handball, and other sports. Barça is not alone; many other sporting activities occur in Barcelona. The city also hosts the first European University of Sport in the Montjuich Olympic Ring.

Let's talk a moment about science- the main reason of your visit. Barcelona and its region of influence, especially the neighboring city of Hospitalet de Llobregat, host five large university hospitals, six universities, and three National Health Research Foundations.

Barcelona is very proud to host the European Nuclear Medicine Congress for the third time. The first was in 1980, 
before the unification of the two European nuclear medicine societies. The second, in 1999, brought together more than 3,000 participants in the south of the city. Finally, for the event in 2009, we expect to surpass 5,000 participants, which is the reason for the change to the new venue. In 2002, this venue hosted the World Culture Forum and provided the city new facilities and space for both work and leisure. Almost 2,000 papers were scored by the scientific committee and distributed among 70 oral sessions and 1,000 posters. Plenary sessions and dedicated symposia will show you the state-of-the-art in nuclear cardiology (the Marie Curie Lecture will be given by Prof. Valentin Fuster), nuclear oncology, therapy with radionuclides, nuclear neurology, inflammation/infection and all the clinical and research applications of nuclear medicine.
The local organization and scientific committees as well as the EANM executive committee and all of us have worked very hard to offer you what we believe will be an excellent congress. Please take advantage of this congress to learn, teach, and communicate with your colleagues to interchange ideas and to open new cooperative projects. The congress will be a unique opportunity to make contact with nuclear medicine professionals from all over the world. You can return home with the happy feeling that you are better, thanks to Barcelona-better in knowledge and in humanity.

From the Nuclear Medicine Department of the Hospital University de Bellvitge, on behalf of the EANM, it is my pleasure to welcome you to the 2009 EANM Congress and wish you a pleasant stay. 